\title{
Proteínas da semente de cupuaçu e alterações devidas à fermentação e à torração
}

\author{
Proteins of cupuacu seeds (Theobroma grandiflorum Schum) and changes during fermentation and roasting
}

\author{
Ana Vânia CARVALHO ${ }^{1 *}$, Nelson Horacio Pezoa GARCÍA² ${ }^{2}$ Jaime Amaya FARFÁN ${ }^{3}$
}

\begin{abstract}
Resumo
O cupuaçu (Theobroma grandiflorum Schum) é um fruto típico da região Norte do Brasil, com grande potencial econômico. Atualmente, é a polpa que mobiliza e sustenta a produção, a industrialização e a comercialização deste fruto. A semente, um subproduto da industrialização da polpa, apresenta teor considerável de proteínas. Entretanto, muito pouco ou nada se conhece acerca de seu perfil eletroforético, de aminoácidos e de principais frações, uma vez que ocorrem alterações protéicas devidas aos processos de fermentação e torração. O objetivo deste estudo consiste em caracterizar as alterações da proteína da semente, da amêndoa fermentada e da amêndoa torrada de cupuaçu, mediante a análise dos perfis eletroforéticos, dos aminogramas característicos e do fracionamento da proteína em diferentes solubilidades. A fermentação e a torração provocaram uma ligeira redução nos teores de proteína total e aminoácidos totais, quando comparados aos teores das sementes não submetidas a essas etapas do processamento. Observou-se, para a semente e a amêndoa fermentada, a presença de quatro bandas protéicas principais de 20,4,33,6 e 38,7 kDa. Para as amêndoas que foram submetidas ao processo de fermentação e, em seguida, à torração, observou-se a presença de uma única banda protéica forte, com peso molecular aparente de $21,0 \mathrm{kDa}$. As extrações para fracionamento das proteínas em diferentes solubilidades não resultaram em frações protéicas puras. Observou-se a presença de quatro bandas principais em todas as frações protéicas isoladas, sendo a banda de peso molecular próximo a $21,1 \mathrm{kDa}$ a mais abundante em todos os casos. Esta banda é aparentemente muito semelhante à fração albumina do cacau, que apresenta peso molecular aparente de $21,3 \mathrm{kDa}$.
\end{abstract}

Palavras-chave: frações protéicas; aminoácidos; eletroforese.

\begin{abstract}
Cupuacu (Theobroma grandiflorum Schum) is a native fruit from northern Brazil with great economic potential. Its productive chain is currently sustained by the pulp market. The seed, treated as a by-product of the pulp industrialization, presents considerably protein content. However, very little or nothing is known on its eletrophoretic profile and amino acids, the main protein fractions and alterations due to the fermentation and toasting. The objective of this study was to characterize protein changes in cupuacu seeds, fermented beans, and roasted beans, through the analysis of the electrophoresis profiles, aminograms, and protein fractionations based on solubility. Fermentation and roasting promoted a slight reduction in the total protein and amino acid contents. The seeds and fermented beans presented four main protein bands with 15.5, 20.4,27.1, and $33.6 \mathrm{kDa}$. The beans submitted to fermentation followed by roasting presented only one strong protein band with an apparent molecular weight of $21.0 \mathrm{kDa}$. The extractions for protein fractionation based on solubility did not result in pure protein fractions. Four main bands were observed in all isolated protein fractions. The $21.1 \mathrm{kDa}$ band was predominant in all cases. This band is apparently very similar to the albumin fraction of cocoa, whose apparent molecular weight is $21.3 \mathrm{kDa}$.
\end{abstract}

Keywords: protein fractions; amino acid; electrophoresis.

\section{Introdução}

O cupuaçuzeiro é uma árvore típica da região amazônica, cultivada nos estados do Pará, Rondônia, Amazonas, Acre e Maranhão. É considerada uma das melhores e mais promissoras árvores fruteiras da Amazônia. O cupuaçu vem se destacando como um dos frutos regionais amazônicos de intensa divulgação no território brasileiro e com grande potencial para a industrialização. O seu valor econômico está baseado, principalmente, na industrialização e comercialização da polpa, apreciada sob a forma de suco, creme, doces e outros processamentos culinários. Apesar de constituírem cerca de $20 \%$ do peso do fruto e possuírem alto valor nutritivo, as sementes são praticamente descartadas no beneficiamento do fruto. Em função de suas propriedades, a semente é considerada valiosa, pois possui semelhança botânica e química com a semente de

cacau, possibilitando a sua utilização na fabricação de produtos similares ao chocolate (COHEN; JACKIX, 2005). O processo de industrialização das sementes de cupuaçu ocorre de modo semelhante ao das sementes de cacau, que inclui as etapas de fermentação, secagem e torração.

A etapa de fermentação das sementes é essencial ao processamento, pois é a etapa responsável pelo desenvolvimento dos precursores e inúmeros compostos de sabor. O processo de fermentação das sementes inicia-se naturalmente pela ação da atividade microbiana na polpa mucilaginosa, que envolve a semente. Os produtos do metabolismo dos microrganismos principalmente álcool, ácidos orgânicos e o calor gerado nos primeiros dias de fermentação provocam a destruição do

${ }^{1}$ Laboratório de Agroindústria, EMBRAPA Amazônia Oriental, Travessa Enéas Pinheiro, s/n, CEP 66095-100, CP 48, Belém - PA, Brasil, E-mail: anavania@cpatu.embrapa.br

2 Departamento de Tecnologia de Alimentos, Universidade Estadual de Campinas - UNICAMP, Campinas - SP, Brasil

${ }^{3}$ Departamento de Alimentos e Nutrição, Universidade Estadual de Campinas - UNICAMP, CEP 13083-970, Campinas - SP, Brasil

${ }^{*}$ A quem a correspondência deve ser enviada 
poder germinativo da semente e desencadeiam importantes transformações físico-químicas e estruturais. Estas transformações afetam significativamente a qualidade do produto final, principalmente os aspectos que envolvem a formação de sabor (SCHWAN, 1996).

Durante a fermentação, observa-se aumento do conteúdo de aminoácidos livres e peptídios em função da quebra das moléculas de proteínas. Há também formação de açúcares redutores pela quebra de sacarose. Estes compostos são conhecidos como os principais precursores do sabor do chocolate ou de análogos. Brito et al. (2001), em um estudo das amêndoas de cacau, observaram que, após 72 horas de fermentação, houve aumento significativo de quase todos os aminoácidos livres, com exceção da tirosina e lisina.

O objetivo deste estudo consiste em caracterizar os principais polipeptídios da semente de cupuaçu antes e após os processos de fermentação e torração, em função de sua solubilidade e peso molecular, além de caracterizar o perfil aminoacídico destes materiais.

\section{Material e métodos}

\subsection{Preparo das sementes in natura, amêndoas fermentadas e amêndoas fermentadas torradas}

As sementes e amêndoas fermentadas foram preparadas na Cooperativa Agrícola Mista de Tomé-Açú (CAMTA), no estado do Pará, Brasil. Para a obtenção das sementes in natura, foi extraído o máximo possível da polpa aderida às sementes, que foram secas ao sol em barcaças de madeira, até atingir umidade entre 7 e $8 \%$. As amêndoas fermentadas foram obtidas segundo a metodologia proposta por Vasconcelos (1999). As sementes de cupuaçu foram fermentadas em caixa de madeira, construída de acordo com Grimaldi (1978), com as seguintes dimensões: $190 \mathrm{~cm}$ de comprimento, $120 \mathrm{~cm}$ de largura e $60 \mathrm{~cm}$ de altura, com espaço entre as tábuas de fundo de $0,2 \mathrm{~cm}$ para escoamento do líquido gerado durante o processo fermentativo. A caixa possui três compartimentos com forma e volume adequados para o processo e capacidade para $160 \mathrm{~kg}$ de sementes. A caixa deve ser colocada sob abrigo de chuva e sol, de modo a proteger as sementes.

Inicialmente, as sementes foram colocadas no primeiro compartimento da caixa, juntamente com folhas picadas de bananeira, para proporcionar a inoculação dos microrganismos existentes na superfície dessas folhas; em seguida, foram cobertas com sacos de aniagem para auxiliar a retenção de calor gerado durante a fermentação. O tempo total do processo foi de 7 dias, com revolvimento das sementes após 48 horas para o segundo compartimento e após 72 horas, para o terceiro compartimento da caixa. Foram determinadas as temperaturas diárias da massa em diferentes níveis (superfície, meio e fundo), com o auxílio de um termômetro de mercúrio. Após a fermentação, as amêndoas foram secas ao sol em barcaça de madeira, até obtenção de umidade final entre 7 e $8 \%$.

A torração das amêndoas fermentadas foi conduzida de acordo com Carvalho, García e Wada (2005).
As sementes, amêndoas fermentadas secas e amêndoas fermentadas torradas foram quebradas e descascadas manualmente para a remoção da testa (casca) e do gérmen. Os cotilédones foram finamente moídos em aparelho de cilindros resfriados (Pilão, Bauru, Brasil) e submetidos à extração da gordura em aparelho de Soxhlet, por 20 horas.

\subsection{Extração das frações protéicas}

A extração seqüencial das proteínas de semente desengordurada de cupuaçu foi realizada como descrito por Pedó (1996). Porções de $20 \mathrm{~g}$ de semente desengordurada de cupuaçu foram submetidas à extração por uma hora em solução de $\mathrm{NaCl} 1 \mathrm{M}$ $(1: 10, p / v)$, sob agitação contínua e temperatura de $5^{\circ} \mathrm{C}$. A seguir, a suspensão foi centrifugada a $15000 \times$ g por 30 minutos a $5{ }^{\circ} \mathrm{C}$, obtendo-se o sobrenadante I e o resíduo I.

O sobrenadante I, com albuminas e globulinas solúveis em soluções levemente salinas, foi dialisado contra água destilada por 48 horas; neste processo, a redução da força iônica do meio induziu a precipitação das globulinas. Após centrifugação do dialisado, o sedimento (fração globulina) e sobrenadante (fração albumina) foram liofilizados.

O resíduo I foi ressuspendido em etanol a 70\%, agitado por uma hora na temperatura ambiente e centrifugado a $15000 \mathrm{x}$ g por 30 minutos à temperatura de $5^{\circ} \mathrm{C}$. Após a centrifugação, foram obtidos o sobrenadante II e o resíduo II. O sobrenadante, após ser liofilizado, constituiu a fração prolamina.

O resíduo II foi ressuspendido em solução formada por dodecil sulfato de sódio $0,5 \%$ e 2 -mercaptoetanol 0,6\%, em $\mathrm{pH} 7,6$, e agitado por uma hora na temperatura ambiente. Após centrifugação a $15000 \times$ g por 30 minutos a $5{ }^{\circ} \mathrm{C}$, obteve-se o sobrenadante III e o resíduo III. O sobrenadante, após ser liofilizado, constitui a fração glutelina.

O resíduo III, constituído basicamente de amido, proteínas insolúveis e substâncias da fração fibra alimentar, foi liofilizado e posteriormente analisado juntamente com as demais frações.

\subsection{Determinação do teor de proteína nas sementes, amêndoas fermentadas, amêndoas torradas e nas frações protéicas}

O teor de proteína foi determinado pelo método semi micro Kjeldahl, baseado na digestão e posterior destilação da amostra (AOAC, 1997).

\subsection{Perfil de aminoácidos da semente, da amêndoa fermentada e da amêndoa torrada}

\section{Composição de aminoácidos totais}

A composição de aminoácidos totais foi determinada por hidrólise ácida da amostra desengordurada, com $\mathrm{HCl} 6 \mathrm{~N}$ a $110^{\circ} \mathrm{C}$, a vácuo, por 22 horas. A amostra foi recuperada em diluente de citrato de sódio $\mathrm{pH}$ 2,2, marca Pickering (SPACKMAN et al., 1958).

As determinações foram feitas utilizando-se cromatógrafo de troca iônica (Thermo Separation Products; Riviera 
Beach, Estados Unidos), com bomba degaseificadora acoplada a um módulo de pré-reação Pickering Laboratories PCX 3100 post-column reaction module (Mountain View, Canadá), operando com detector de UV, nos comprimentos de onda de 440 e $570 \mathrm{~nm}$, modelo Spectro System UV2000. Foi utilizada coluna analítica Pickering Laboratories $1193250\left(\mathrm{Na}^{+} 8 \mu \mathrm{m}\right.$, $3 \mathrm{~mm}$ ID x $250 \mathrm{~mm}$ ), acoplada a uma pré-coluna Pickering Laboratories $1192020\left(\mathrm{Na}^{+} 8 \mu \mathrm{m}, 2 \mathrm{~mm}\right.$ ID x $\left.20 \mathrm{~mm}\right)$. Soluções de $\mathrm{Na}(3,15 ; 7,4$ e $0,2 \mathrm{~N})$ foram utilizadas com um fluxo de $0,3 \mathrm{~mL} / \mathrm{min}$ a $55^{\circ} \mathrm{C}$ na coluna e $130^{\circ} \mathrm{C}$ no reator.

\section{Triptofano}

O aminoácido triptofano foi determinado após hidrólise enzimática com pronase, a $40{ }^{\circ} \mathrm{C}$, por 24 horas, seguida de reação colorimétrica, na ausência de luz, com dimetilamino benzaldeído (DAB) e nitrito de sódio, com posterior leitura em espectrofotômetro, a $540 \mathrm{~nm}$ (SPIES, 1967).

\subsection{Eletroforese em gel de poliacrilamida (SDS-PAGE)}

A determinação do perfil eletroforético das proteínas da semente, da amêndoa fermentada, da amêndoa torrada e das frações protéicas foi realizada de acordo com Laemmli (1970), com algumas modificações; utilizou-se, neste processo, o Sistema Mini-Protean II com fonte Bio Rad (Oregon, Estados Unidos). As amostras (0,4\% de proteína) foram dispersas em $1 \mathrm{~mL}$ de solução tampão, formada por $42,5 \%$ de água destilada, $12,5 \%$ de Tris- $\mathrm{HCl} 0,5 \mathrm{M}$ (pH 6,8), $20 \%$ de glicerol, $20 \%$ de SDS, $5 \%$ de $\beta$-mercaptoetanol e $0,1 \%$ de bromofenol; a seguir, as amostras foram aquecidas a $95{ }^{\circ} \mathrm{C}$ por 5 minutos e, após resfriamento, alíquotas de $5 \mu \mathrm{L}$ de cada amostra foram aplicadas no gel. Utilizou-se o gel de separação a 12\% e o gel de empilhamento a $4 \%$. Após a corrida, os géis foram mantidos em solução corante de Brillant Blue G a 0,1\% em ácido fosfórico por 24 horas e, a seguir, descorados em água destilada.

Os pesos moleculares da proteína foram determinados utilizando-se o padrão Pharmacia (17-0446-01): fosforilase b (97 kDa), albumina sérica bovina $(66 \mathrm{kDa})$, ovalbumina $(45 \mathrm{kDa})$, anidrase carbônica $(30 \mathrm{kDa})$, inibidor de tripsina $(20,1 \mathrm{kDa})$ e $\alpha$-lactalbumina $(14,4 \mathrm{kDa})$.

A densitometria dos géis foi realizada em densitômetro Sharp JX 330, empregando-se o software Image Master (Pharmacia) (Upsala, Suécia), para calcular os pesos moleculares aparentes de cada banda, segundo comparação com os pesos moleculares da proteína-padrão.

\subsection{Eletroforese em sistema SDS-PAGE-tricina}

Proteínas e oligopeptídios com massa molecular abaixo de $14 \mathrm{kDa}$ não apresentam boa resolução em sistema SDS-PAGE, como descrito por Laemmli (1970), e também em sistema de gradiente de gel.

O procedimento descrito por Schagger e Jagow (1987) no qual o íon carregador, a glicina, do sistema de Laemmli, é substituído por tricina apresenta boa resolução para peptídios na faixa de 1 a $100 \mathrm{kDa}$. Além desta substituição do íon carregador, são empregados três géis: gel de separação, gel espaçador e gel de empilhamento.

Dessa forma, o perfil eletroforético dos peptídios de peso molecular inferior a $14 \mathrm{kDa}$ foi realizado de acordo com Schagger e Jagow (1987), utilizando-se o gel de separação a $16,5 \%$ de acrilamida e 3\% de bis-acrilamida, o gel espaçador a $10 \%$ de acrilamida e $3 \%$ de bis-acrilamida e o gel de empilhamento a $4 \%$ de acrilamida e $3 \%$ de bis-acrilamida. Após a corrida, os géis foram mantidos em solução corante de Brilhante Blue $\mathrm{G}$ a $0,1 \%$ em ácido fosfórico por 24 horas e, a seguir, descorados em água destilada.

Os pesos moleculares da proteína foram determinados utilizando-se o padrão Pharmacia (80-1129-83): globulina I + II (14404 Da), globulina I + III (10700 Da), globulina I (8159 Da), globulina II (6214 Da), globulina III (2512 Da). A densitometria dos géis foi efetuada em densitômetro Sharp JX 330, empregando-se o software Image Master (Pharmacia) (Upsula, Suécia) para calcular os pesos moleculares aparentes de cada banda, em relação à proteína-padrão.

\section{Resultados e discussão}

\subsection{Eletroforese das frações isoladas da semente de cupuaçu}

A Tabela 1 apresenta os valores médios da quantidade de proteína extraída e o teor protéico de cada uma das frações obtidas da tentativa de fracionamento da proteína de semente de cupuaçu, a partir de $20 \mathrm{~g}$ de farinha desengordurada. É pertinente ressaltar que as extrações não resultaram em frações protéicas puras. Esta ocorrência é relativamente comum, pois o maior ou o menor grau de separação é característico de cada fonte protéica e, neste caso, as proteínas de cupuaçu mostram ser de difícil separação pelo método empregado. Assim, cada uma das frações foi corrigida pelo fator de pureza correspondente (teor de proteína da amostra ou resíduo): 54,15 para a fração albumina; 42,81 para a fração globulina; 11,87 para a fração prolamina; 17,92 para a fração glutelina, e 20,51 para o resíduo III.

O perfil eletroforético e os pesos moleculares calculados para cada uma das frações isoladas no fracionamento da proteína de semente de cupuaçu estão apresentados na Figura 1 e na Tabela 2, respectivamente.

Para fins comparativos de duas espécies similares, foi realizada a eletroforese de semente de cacau, de semente de cupuaçu e das frações protéicas obtidas a partir da semente de cupuaçu (Figura 1 e Tabela 2).

Observou-se a presença de quatro bandas principais em todas as frações protéicas isoladas, com pesos moleculares próximos a 16,1, 21,2, 34,8 e 40,5 $\mathrm{kDa}$. A banda de peso molecular próximo dos $21,1 \mathrm{kDa}$ foi a mais abundante em todos os casos. Esta banda é aparentemente muito semelhante à da fração albumina do cacau, que apresenta peso molecular aparente de $21,3 \mathrm{kDa}$. Notou-se, ainda, na fração tida como globulina, a presença de duas bandas fracas com pesos moleculares aparentes de 28,3 e 63,6 kDa. Para o resíduo III, verificou-se, além das bandas presentes nas demais frações, a presença de quatro 
Tabela 1. Quantidade de proteína extraída e teor protéico em cada uma das frações isoladas no fracionamento da proteína de semente de cupuaçu, a partir de $20 \mathrm{~g}$ de farinha desengordurada.

\begin{tabular}{lrrrrr} 
& \multicolumn{3}{c}{ Frações protéicas } \\
\cline { 2 - 6 } & Albumina & Globulina & Prolamina & \multicolumn{1}{c}{ Glutelina } & \multicolumn{1}{c}{ Resíduo III } \\
\hline Proteína extraída (\%) & $3,5 \pm 0,11$ & $0,65 \pm 0,10$ & $2,75 \pm 0,83$ & $1,50 \pm 0,19$ & $11,70 \pm 0,44$ \\
Proteína na amostra (\%) & $54,15 \pm 0,22$ & $42,81 \pm 0,17$ & $11,87 \pm 0,13$ & $17,92 \pm 0,17$ & $20,51 \pm 0,23$ \\
\hline
\end{tabular}

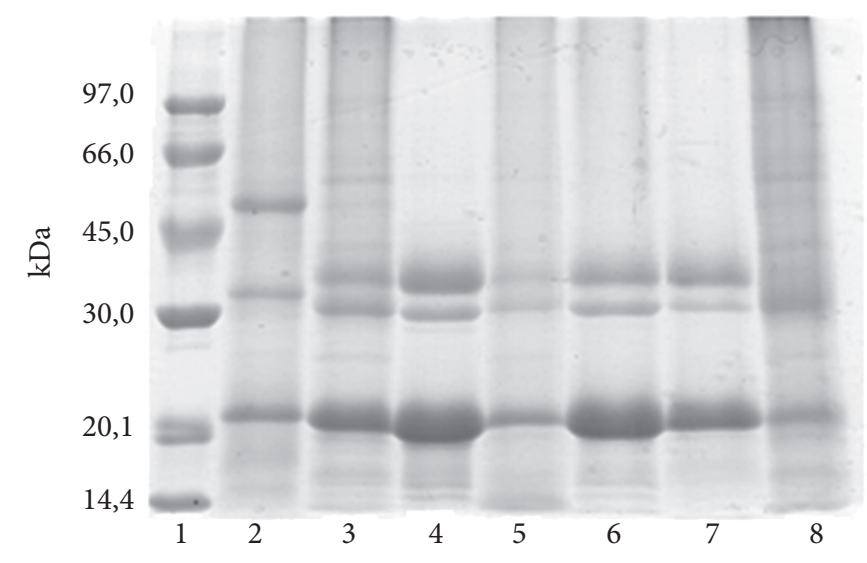

Figura 1. Perfil eletroforético das frações protéicas de cupuaçu, em gel de poliacrilamida - SDS. Coluna 1: padrão Pharmacia (17-0446-01); coluna 2: semente de cacau; coluna 3: semente de cupuaçu; coluna 4: albumina; coluna 5: globulina; coluna 6: prolamina; coluna 7: lutelina; e coluna 8: resíduo III.

bandas com pesos moleculares maiores e que estão presentes também na semente de cupuaçu.

Observa-se no perfil eletroforético das proteínas (Figura 1) que o fracionamento realizado neste estudo resultou em frações protéicas bastante impuras. Dessa forma, poucas conclusões podem ser feitas com relação às frações protéicas do cupuaçu.

Voigt, Biehl e Wazir (1993), em um estudo das principais proteínas do cacau, encontraram que as frações albumina e globulina ocorriam em proporções de 52 e $43 \%$ do total das proteínas da semente, respectivamente. A mais importante albumina é um polipeptídio com peso molecular aparente de $19 \mathrm{kDa}$, presumivelmente idêntico ao polipeptídio de $21 \mathrm{kDa}$ já relatado em estudos acerca do cacau de outros autores e cuja seqüência de aminoácidos já foi reportada (SPENCER; HODGE, 1991).

Diferentemente, a fração globulina contém polipeptídios com pesos moleculares aparentes de 14,5, 31 e $47 \mathrm{kDa}$, e possui globulinas somente do tipo vicilina. Não foi detectada a fração prolamina e nem confirmada a existência de glutelina, apesar de, em trabalhos anteriores (ZAK; KEENEY, 1976a,b), a fração prolamina ter sido identificada em sementes de cacau e a proporção da fração glutelina apresentar-se consideravelmente maior ao valor encontrado por Voigt, Biehl e Wazir (1993), que foi cerca de $5 \%$ do total das proteínas.

\subsection{Efeito da fermentação e da torração no teor de proteínas e perfil de aminoácidos da semente de cupuaçu}

Os perfis de aminoácidos totais encontrados na semente, na amêndoa fermentada e na amêndoa torrada do cupuaçu, e o teor de proteína total estão apresentados na Tabela 3. Nas sementes não fermentadas, os teores de proteína encontram-se superiores quando comparados aos teores do material submetido à fermentação e daquele submetido a fermentação e torração. Vasconcelos (1999) verificou que o teor de proteína total nas sementes de cupuaçu varia ligeiramente durante a fermentação, sendo observado um pequeno decréscimo. Diversamente, Lerceteau et al. (1999), ao estudarem as proteínas do cacau durante o processo de fermentação, observaram que o teor total de proteína diminuiu para $57 \%$ do valor inicial durante o período de fermentação.

As etapas de fermentação e torração provocaram uma ligeira redução nos teores de aminoácidos totais, quando comparados aos teores de sementes que não foram submetidas a essas etapas de processamento (Tabela 3). Vasconcelos (1999), ao estudar as transformações físicas e químicas durante a fermentação de amêndoas de cupuaçu, observou uma pequena redução no teor da maioria dos aminoácidos durante o processo fermentativo, à exceção dos aminoácidos serina, glicina, metionina, fenilalanina e arginina, que apresentaram uma discreta elevação. Brito et al. (2001) constataram que o perfil de aminoácidos de amêndoas de cacau permanecia praticamente inalterado quando comparado ao perfil da semente, apesar das importantes alterações ocorridas durante o processo fermentativo.

A destruição de alguns aminoácidos durante a hidrólise ácida limita sua quantificação para avaliação do ponto de vista nutricional, pois alguns aminoácidos essenciais são parcial (metionina, cisteína, treonina e tirosina) ou totalmente destruídos (triptofano).

De acordo com os dados apresentados, a valina e a histidina foram os aminoácidos limitantes para sementes de cupuaçu, conforme o padrão de referência para crianças na faixa etária de 1 a 3 anos (IMA, 2002). Para as amêndoas fermentadas e amêndoas fermentadas e torradas, além da valina e da histidina, observou-se redução nos teores do aminoácido lisina, que passa também a ser considerado limitante após os processos de fermentação e torração.

Lopes, Pezoa-García e Amaya-Farfán (2008), em um estudo das amêndoas fermentadas e torradas de cupuaçu e cacau, relataram como aminoácidos limitantes para o cupuaçu a lisina e histidina; observaram, no entanto, teores superiores ao 
Tabela 2. Pesos moleculares aparentes $(\mathrm{kDa})$ das proteínas de semente de cacau, de semente de cupuaçu e das frações isoladas de semente de cupuaçu, calculados por densitometria.

\begin{tabular}{|c|c|c|c|c|c|c|}
\hline \multicolumn{7}{|c|}{ Espécime } \\
\hline Cacau & Cupuaçu & Albumina S-I & Globulina R-I & Prolamina S-II & Glutelina S-III & Resíduo R-III \\
\hline 17,7 & 16,2 & 16,1 & 16,4 & 16,2 & 17,1 & 17,3 \\
\hline 21,3 & 21,7 & 21,1 & 21,5 & 21,5 & 22,2 & 22,3 \\
\hline * & 27,8 & * & 28,3 & * & * & 29,2 \\
\hline 37,3 & 35,3 & 34,8 & 35,6 & 35,6 & 36,5 & 35,8 \\
\hline 55,3 & 40,5 & 39,5 & 41,4 & 41,7 & 42,3 & * \\
\hline * & 45,9 & * & * & * & * & 47,9 \\
\hline * & 54,9 & * & * & * & * & 56,9 \\
\hline * & 61,8 & * & 63,6 & * & * & 64,6 \\
\hline * & 88,9 & * & * & * & * & 90,9 \\
\hline
\end{tabular}

${ }^{\star}$ Bandas não detectadas.

Tabela 3. Teor de proteína total (\%) e aminoácidos totais $\left(\mathrm{mg} \cdot \mathrm{g}^{-1}\right.$ proteína) das sementes, amêndoas fermentadas, amêndoas fermentadas e torradas de cupuaçu, em base seca e desengordurada, e padrão de referência (IMA, 2002).

\begin{tabular}{|c|c|c|c|c|c|c|}
\hline \multirow[t]{2}{*}{ Aminoácidos } & \multicolumn{6}{|c|}{ Teor de aminoácidos } \\
\hline & Semente de cupuaçu & Cupuaçu fermentado & Cupuaçu torrado & Cupuaçu torrado* & Cacau torrado ${ }^{*}$ & IMA $^{\mathrm{a}}$ \\
\hline \multicolumn{7}{|l|}{ Indispensáveis } \\
\hline Treonina & $59,20 \pm 0,4$ & $57,21 \pm 1,5$ & $56,66 \pm 1,1$ & 53 & 36 & 27 \\
\hline Valina & $72,60 \pm 1,5$ & $63,36 \pm 3,7$ & $60,63 \pm 0,3$ & 56 & 51 & 32 \\
\hline Metionina & $4,59 \pm 1,1$ & $4,26 \pm 1,1$ & $2,49 \pm 0,6$ & 16 & 11 & $25^{\mathrm{b}}$ \\
\hline Cistina & $23,31 \pm 0,4$ & $22,70 \pm 1,2$ & $22,86 \pm 1,2$ & 19 & 12 & \\
\hline Isoleucina & $45,8 \pm 0,3$ & $41,61 \pm 0,4$ & $42,24 \pm 0,8$ & 43 & 35 & 25 \\
\hline Leucina & $84,4 \pm 1,5$ & $77,07 \pm 1,5$ & $79,52 \pm 1,5$ & 70 & 53 & 55 \\
\hline Tirosina & $37,06 \pm 0,7$ & $43,50 \pm 1,5$ & $42,74 \pm 1,1$ & 36 & 30 & \\
\hline Fenilalanina & $45,47 \pm 0,3$ & $41,13 \pm 0,4$ & $40,26 \pm 0,3$ & 37 & 38 & $47^{\mathrm{c}}$ \\
\hline Lisina & $53,11 \pm 1,5$ & $45,39 \pm 4,7$ & $43,74 \pm 0,3$ & 46 & 54 & 51 \\
\hline Histidina & $14,52 \pm 0,7$ & $12,77 \pm 1,5$ & $11,43 \pm 1,2$ & 14 & 14 & 18 \\
\hline Triptofano & $12,99 \pm 0,1$ & $14,60 \pm 0,7$ & $12,92 \pm 0,4$ & - & - & 8 \\
\hline \multicolumn{7}{|l|}{ Não indispensáveis } \\
\hline Arginina & $56,55 \pm 1,5$ & $56,74 \pm 3,7$ & $52,68 \pm 0,4$ & - & - & - \\
\hline Ácido aspártico & $123,81 \pm 2,6$ & $144,21 \pm 3,4$ & $151,59 \pm 1,5$ & - & - & - \\
\hline Serina & $53,11 \pm 3,4$ & $59,57 \pm 2,3$ & $58,15 \pm 2,2$ & - & - & - \\
\hline Ácido glutâmico & $148,26 \pm 1,1$ & $141,37 \pm 3,7$ & $147,11 \pm 3,4$ & - & - & - \\
\hline Prolina & $44,33 \pm 2,2$ & $52,01 \pm 1,5$ & $51,19 \pm 8,9$ & - & - & - \\
\hline Glicina & $57,70 \pm 0,3$ & $60,99 \pm 6,1$ & $62,13 \pm 0,8$ & - & - & - \\
\hline Alanina & $47,76 \pm 0,3$ & $45,86 \pm 2,2$ & $47,22 \pm 0,8$ & - & - & - \\
\hline Amônia & $15,28 \pm 0,7$ & $14,66 \pm 0,4$ & $14,41 \pm 0,8$ & - & - & - \\
\hline Proteína total & $26,17 \pm 0,3$ & $21,15 \pm 0,8$ & $20,12 \pm 0,5$ & - & - & - \\
\hline
\end{tabular}

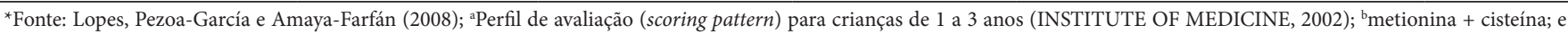
cfenialanina + tirosina.

teor encontrado neste trabalho para o aminoácido valina. Os Autores observaram ainda que o cupuaçu apresentou, para os aminoácidos indispensáveis, teores mais elevados que o cacau, com exceção de lisina, histidina e fenilalanina. Eles constataram também que as proteínas da semente do cupuaçu possuem composição aminoacídica que supera a composição das sementes do cacau no que diz respeito aos aminoácidos leucina, isoleucina e tirosina, que são aminoácidos limitantes para o cacau. $\mathrm{O}$ fato de terem relatado um maior valor biológico para as proteínas do cupuaçu em comparação às proteínas do cacau incrementou os estudos com ratos, o que indica a pesquisa e a busca da verificação de um considerável potencial nutricional das proteínas da semente deste fruto.
3.3 Eletroforese em gel de poliacrilamida-SDS-PAGE e em gel de poliacrilamida-SDS-tricina da semente, da amêndoa fermentada e da amêndoa fermentada e torrada de cupuaçu

O perfil eletroforético da proteína da semente, da amêndoa fermentada e da amêndoa fermentada e torrada de cupuaçu pode ser observado na Figura 2.

Observou-se, para a semente de cupuaçu, a presença de um total de nove bandas protéicas, sendo três bandas principais, com pesos moleculares aparentes próximos a 20,4, 33,6 e $38,7 \mathrm{kDa}$. Notou-se também a presença de mais seis bandas fracas de maior peso molecular $(15,5,38,7,44,3,54,4,60,8$, e $83,4 \mathrm{kDa})$. 
Para a amêndoa submetida à fermentação, verificou-se também a presença de três principais bandas protéicas, com pesos moleculares aparentes similares ao observado para a semente: 20,7,34,0 e 39,2 kDa, e duas bandas tênues, de pesos moleculares próximos a 15,9 e 27,2 $\mathrm{kDa}$.

Na Tabela 4, estão indicados os pesos moleculares das proteínas e, na Tabela 5, a área de cada banda protéica.

Em relação às amêndoas que foram submetidas ao processo de torração, observou-se, no perfil eletroforético das proteínas

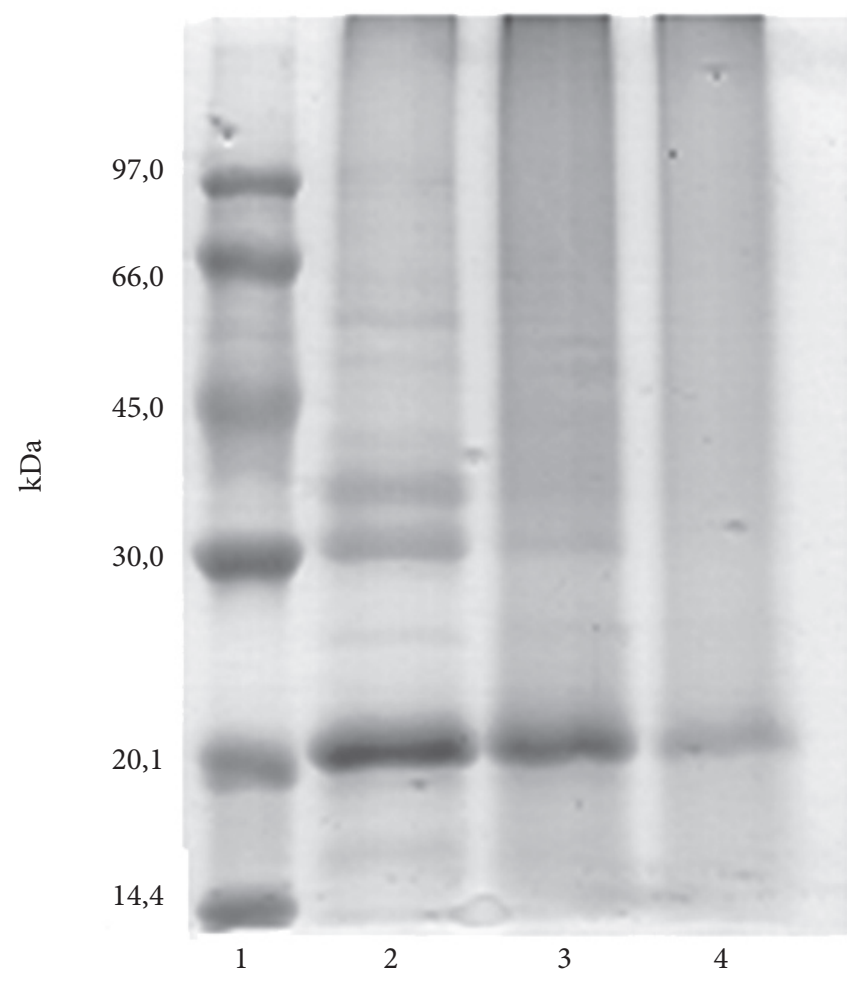

Figura 2. Perfil eletroforético da proteína da semente, da amêndoa fermentada e da amêndoa fermentada e torrada de cupuaçu, em gel de poliacrilamida-SDS; coluna 1: padrão Pharmacia (17-0446-01); coluna 2: semente de cupuaçu; coluna 3: amêndoa fermentada de cupuaçu; e coluna 4: amêndoa fermentada e torrada de cupuaçu.

Tabela 4. Pesos moleculares aparentes $(\mathrm{kDa})$ das proteínas da semente, da amêndoa fermentada e da amêndoa fermentada e torrada de cupuaçu, calculados através da densitometria do gel.

\begin{tabular}{ccc}
\hline Semente & Amêndoa fermentada & Amêndoa torrada \\
\hline 15,5 & 15,9 & $\star$ \\
20,4 & 20,7 & 21,1 \\
27,0 & 27,2 & $\star$ \\
33,6 & 34,0 & $\star$ \\
38,7 & 39,2 & $*$ \\
44,3 & $\star$ & $\star$ \\
54,4 & $\star$ & $\star$ \\
60,8 & $\star$ & $\star$ \\
83,4 & $\star$ & $\star$ \\
\hline
\end{tabular}

*Abaixo do limite de quantificação.
(Figura 2), a presença de uma única banda protéica forte, com peso molecular aparente de 21,0 kDa. Para as demais bandas, seu desaparecimento pode ser atribuído provavelmente à ocorrência de reações durante o processo de torração, como a reação de Maillard complexação de proteínas com compostos polifenólicos, além da possível formação de diversos polímeros. Estas várias reações que ocorrem durante a torração podem produzir insolubilização e menor extratibilidade da proteína, por ocasião do preparo da amostra a ser aplicada no gel. Além disso, não se descarta a possibilidade de que as reações tenham produzido polímeros de grande peso molecular, incapazes de penetrar no gel e, assim, serem excluídos da corrida eletroforética.

Pettipher (1990), ao estudar a extração e a parcial purificação das proteínas de reserva do cacau, encontrou, por meio da SDS-PAGE, a presença de duas proteínas de reserva, S1 e S2, com pesos moleculares aparentes de 28 e $48 \mathrm{kDa}$, respectivamente. Estes pesos moleculares estão próximos aos encontrados por Biehl, Wewetzer e Passern (1982), de 26 e 44 kDa. Segundo Pettipher (1990), estas proteínas de reserva estão presentes nas sementes, porém são ausentes nas folhas e nas sementes germinadas. A densitometria do gel mostrou que as proteínas de reserva S1 e S2 representam aproximadamente 19 e $17 \%$ do total da proteína, respectivamente. Segundo o Autor, outra importante proteína - não considerada uma proteína de reserva, uma vez que ela não foi utilizada durante a germinação - representa cerca de $20 \%$ do total de proteína. Similarmente ao ocorrido na germinação, durante a fermentação do cacau observou-se também uma perda total das proteínas de reserva S1 e S2. Este fato indica que estas proteínas são preferencialmente degradadas por ocasião do processo fermentativo.

Lerceteau et al. (1999), em um estudo das proteínas da semente de cacau, encontraram resultados diferentes: cinco grupos predominantes de polipeptídios, com pesos moleculares de 14,5; 16,5; 21; 31, e $47 \mathrm{kDa}$. Os Autores relatam que, ao final da fermentação, os polipeptídios com pesos moleculares de $14,5,31,0$ e $47 \mathrm{kDa}$ estavam ausentes, fato indicativo de que estes, provavelmente, sejam polipeptídios de armazenamento e que foram clivados em subunidades menores.

Na Figura 3, é possível observar o perfil eletroforético dos peptídios.

Tabela 5. Área de cada banda protéica relativa à área total da proteína da semente, da amêndoa fermentada e da amêndoa fermentada e torrada, calculada a partir da densitometria do gel.

\begin{tabular}{cccc}
\hline Bandas & \multicolumn{3}{c}{ Bandas (\%) } \\
\cline { 2 - 4 }$(\mathrm{PM})$ & Semente & Amêndoa fermentada & Amêndoa torrada \\
\hline $15,5-15,9$ & 9,79 & 10,79 & $*$ \\
$20,4-21,1$ & 40,77 & 47,99 & 100,00 \\
$27,0-27,2$ & 4,92 & 23,56 & $*$ \\
$33,6-34,0$ & 14,47 & 10,02 & $*$ \\
$38,7-39,2$ & 11,57 & 7,64 & $*$ \\
44,3 & 5,43 & $*$ & $*$ \\
54,4 & 4,09 & $*$ & $*$ \\
60,8 & 6,61 & $*$ & $*$ \\
83,4 & 2,34 & $*$ & $*$ \\
\hline
\end{tabular}

*Abaixo do limite de quantificação. 
Observou-se no perfil eletroforético da semente e da amêndoa fermentada (Figura 3), a presença de cinco bandas fracas com pesos moleculares aparentes próximos a 7,2; 8,6; 10,1;12,0, e $14,0 \mathrm{kDa}$, que provavelmente correspondam a fragmentos protéicos ou peptídios (Tabela 6). Diferentemente, nas amêndoas submetidas a fermentação e torração, houve diminuição progressiva de todas as bandas, especialmente das de maior peso molecular. Na medida em que estas bandas não foram detectadas na densitometria do gel, suspeita-se que, no caso dessas bandas corresponderem a peptídios, os mesmos tenham participado da reação de Maillard por serem mais reativos. Formariam dessa forma, polímeros de maior peso molecular durante o processo de torração.

Voigt, Biehl e Wazir (1993), em um estudo das principais proteínas do cacau durante o processo fermentativo, observaram uma perda quase total das globulinas, fato que indica uma digestão proteolítica seletiva, uma vez que a fração albumina praticamente não sofreu alteração quantitativa. Os Autores

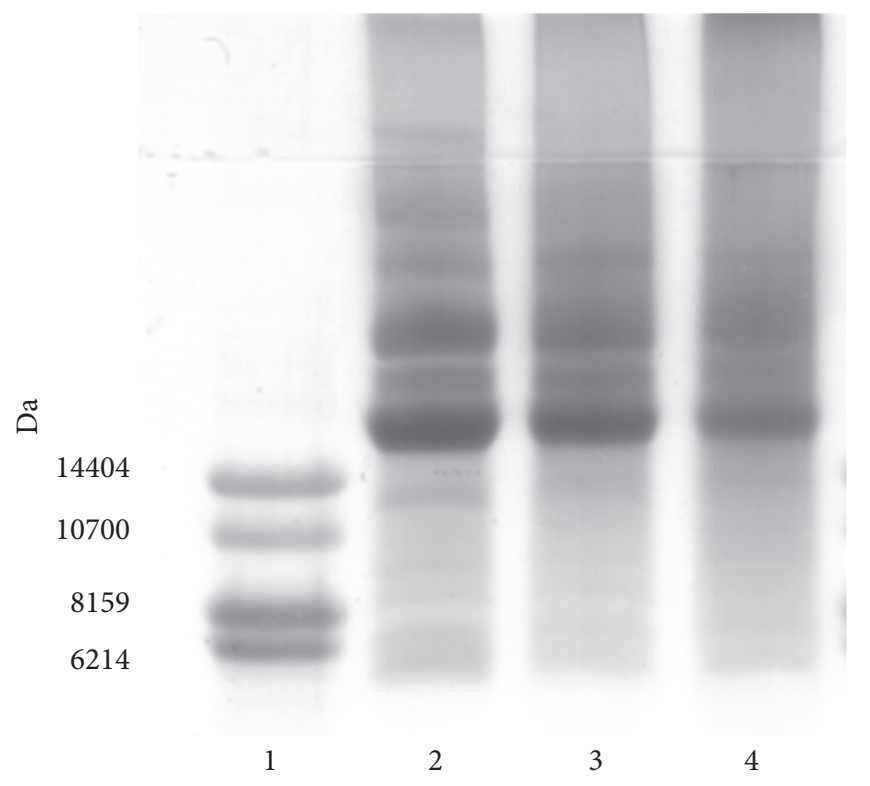

Figura 3. Perfil eletroforético dos peptídios da semente, da amêndoa fermentada e da amêndoa fermentada e torrada de cupuaçu, em gel de poliacrilamida-SDS-tricina; coluna 1: padrão Pharmacia (80-1129-3); coluna 2: semente de cupuaçu; coluna 3: amêndoa fermentada de cupuaçu; e coluna 4: amêndoa torrada de cupuaçu.

Tabela 6. Pesos moleculares aparentes $(\mathrm{kDa})$ dos peptídios da semente, da amêndoa fermentada e da amêndoa fermentada e torrada de cupuaçu, calculados da densitometria do gel.

\begin{tabular}{ccc}
\hline \multicolumn{3}{c}{ Pesos moleculares $(\mathrm{kDa})$} \\
\hline Semente & Amêndoa fermentada & Amêndoa torrada \\
\hline 7,3 & 7,2 & $*$ \\
8,6 & 8,6 & $\star$ \\
10,0 & 10,2 & $\star$ \\
11,3 & 12,6 & $\star$ \\
13,8 & 14,4 & $\star$ \\
\hline
\end{tabular}

*Abaixo do limite de quantificação. sugerem que as globulinas, possivelmente, sejam a fonte dos precursores para a formação do sabor característico do cacau.

Amin, Jinap e Jamilah (1997), ao estudarem sementes de cacau, também observaram a degradação da fração vicilina $(39,2$ e $47,1 \mathrm{kDa})$ durante a fermentação do cacau, e a fração albumina como a mais resistente à proteólise. Ao final da fermentação, o polipeptídio de $39,2 \mathrm{kDa}$ foi completamente degradado, mas o de peso molecular de $47,1 \mathrm{kDa}$ ainda estava presente em baixa intensidade, o que indica que ambos são importantes para a formação de precursores do sabor do cacau. A fração de peso molecular $21 \mathrm{kDa}$ tem sido caracterizada como um inibidor de tripsina (SPENCER; HODGE, 1991; TAI et al., 1991; DODÔ; FRITZ; FURTEK, 1992).

\section{Conclusões}

- Os processos de fermentação e torração das sementes de cupuaçu provocaram redução nos teores da maioria dos aminoácidos indispensáveis, com destaque para a lisina e a valina, que apresentaram perdas em torno de $15 \%$. Com relação à metionina, observou-se, em média, $40 \%$ de perdas devido ao processo de torração;

- As sementes e amêndoas de cupuaçu apresentaram boa composição aminoacídica. A valina e a histidina foram os aminoácidos limitantes para as sementes in natura. Nas amêndoas fermentadas e amêndoas fermentadas e torradas, além da valina e da histidina, a lisina também se apresentou como limitante;

- Para as proteínas da semente e da amêndoa fermentada de cupuaçu, verificou-se a presença de três bandas eletroforéticas principais, com pesos moleculares próximos a 20,4, 33,6 e $39 \mathrm{kDa}$. Nas amêndoas fermentadas e torradas, observou-se perfil eletroforético das proteínas com somente uma banda protéica forte, com peso molecular aparente de 21,1 kDa; e

- As extrações para fracionamento das proteínas em diferentes meios de solubilidades resultaram em frações protéicas impuras. A presença de quatro bandas principais em todas as frações protéicas isoladas $(16,1 ; 21,2 ; 34,8$, e $40,5 \mathrm{kDa})$ foi observada, sendo a banda de peso molecular próximo a $21,1 \mathrm{kDa}$ a mais abundante em todos os casos. Esta banda é muito semelhante à da fração albumina do cacau, que apresenta peso molecular aparente de $21,3 \mathrm{kDa}$.

\section{Agradecimentos}

Os autores agradecem à Fundação de Apoio à Pesquisa do Estado de São Paulo (FAPESP), pela concessão da bolsa de doutorado para Ana Vânia Carvalho.

\section{Referências bibliográficas}

AOAC. Official methods of analysis of the Association of OfficialAOAC. Official methods of analysis of the Association of Official Analytical Chemists. 16 ed. Washington, 1997.

AMIN, I.; JINAP, S; JAMILAH, B. Vicilin-class globulins and their degradation during cocoa fermentation. Food Chemistry, v. 59, n. 1, p. 1-5, 1997. 
BIEHL, B.; WEWETZER, C.; PASSERN, D. Vacuolar (Storage) proteins of cocoa seeds and their degradation during germination and fermentation. Journal of the Science of Food and Agriculture, v. 33, p. 1291-1304, 1982.

BRITO, E. S. et al. Structural and chemical changes in cocoa (Theobroma cacao L) during fermentation, drying and roasting. Journal of the Science of Food and Agriculture, v. 81, n. 2, p. 281-288, 2001.

CARVALHO, A. V.; GARCÍA, N. H. P.; WADA, J. K. A. Caracterização físico-química e curvas de solubilidade protéica de sementes, amêndoas fermentadas e torradas de cupuaçu (Theobroma grandiflorum Schum). Brazilian Journal of Food Technology, v. 8, n. 2, p. 127-134, 2005.

COHEN, K. O.; JACKIX, M. N. H. Estudo do liquor de cupuaçu. Ciência e Tecnologia de Alimentos, v. 25, n. 1, p. 182-190, 2005.

DODO, H. W.; FRITZ, P. J.; FURTEK, D. B. A cocoa 21 kilodalton seed protein has trypsin inhibitory activity. Café Cacao Thé, v. 36, p. 279-284, 1992.

GRIMALDI, J. Les possibilités D'amélioration des techniques D'ecabossage et de fermentation dans le processus artisanal de la préparation du cacao. Café Cacao Thé, v. 22, p. 303-316, 1978.

INSTITUTE OF MEDICINE OF THE NATIONAL ACADEMIES. Protein and amino acids. In: Dietary reference intakes for energy, carbohydrate, fiber, fat, fatty acids, cholesterol, protein, and amino acids. Washington: The National Academies Press, 2002. Part 2, chap 10, p. 1-143.

LAEMMLI, U. K. Clevage of structural proteins during the assembly of the head of bacteriophage T4. Nature, v. 227, p. 680-685, 1970.

LERCETEAU, E. et al. Evolution of cacao bean proteins during fermentation: a study by two-dimensional electrophoresis. Journal of the Science of Food and Agriculture, v. 79, n. 4, p. 619-625, 1999.

LOPES, A. S.; PEZOA-GARCÍA, N. H.; AMAYA-FARFÁN, J. Qualidade nutricional das proteínas de cupuaçu e de cacau. Ciência e Tecnologia de Alimentos, v. 28, n. 2, p. 1-6, 2008.

PEDÓ, I. Caracterização química e nutricional de novos cultivares de aveia (Avena sativa, L.). Campinas, 1996. 112p. Dissertação -
(Mestrado em Ciência da Nutrição), Faculdade de Engenharia de Alimentos, Universidade Estadual de Campinas - UNICAMP.

PETTIPHER, G. L. The extraction and partial purification of cocoa storage proteins. Café Cacao Thé, v. 34, n. 1, p. 23-26, 1990.

SCHAGGER, H.; JAGOW, G. Tricine-sodium dodecyl sulfatepolyacrylamide gel eletrophoresis for the separation of proteins in the range from 1 to $100 \mathrm{kDa}$. Analytical Biochemistry, v. 166 , p. 368-379, 1987.

SCHWAN, R. F. Microbiology of cocoa fermentation: a study to improve quality. In: CONFERÊNCIA INTERNACIONAL DE PESQUISA EM CACAU, 12, Salvador, BA, nov. 1996. Anais... Salvador: CEPLAC, 1996.

SPACKMAN, D. H.; STEIN, W. H.; MOORE, S. Automatic recording apparatus for use in the chromatography of amino acids. Analytical Chemistry, v. 30, n. 3, p. 1190-1206, June 1958.

SPENCER, M. E.; HODGE, R. Cloning and sequencing of the cDNA encoding the major albumin of Theobroma cacao. Planta, v. 183, p. 528-535, 1991.

SPIES, J. R. Determination of tryptophan in proteins. Analytical Chemistry, Washington, v. 39, p. 1412-1415, 1967.

TAI, H. et al. Nucleic acid sequence of a $21 \mathrm{kDa}$ cocoa seed protein with homology to the soybean trypsin inhibitor (Kunitz) family of protease inhibitors. Plant Molecular Biology, v. 16, p. 913-915, 1991.

VASCONCELOS, M. A. M. Transformações físicas e químicas durante a fermentação de amêndoas de cupuaçu (Theobroma grandiflorum Schum). Campinas, 1999. 114p. Dissertação (Mestrado em Tecnologia de Alimentos), Faculdade de Engenharia de Alimentos, Universidade Estadual de Campinas - UNICAMP.

VOIGT, J.; BIEHL, B.; WAZIR, S. K. S. The major seed proteins of Theobroma cacao L. Journal Food Chemistry, v. 47, p. 145-151, 1993.

ZAK, D. K.; KEENEY, P. G. Extraction and fractionation of cocoa proteins as applied to several varieties of cocoa beans. Journal of Agricultural and Food Chemistry, v. 24, p. 479-482, 1976a.

Changes in cocoa proteins during ripening of fruit, fermentation, and further processing of cocoa beans. Journal of Agricultural and Food Chemistry, v. 24, p. 483-486, 1976 b. 